\title{
THE CURRENT STATUS OF SOCIAL RISKS ON EDUCATIONAL SYSTEMS. AN ANALYSIS THROUGH SOCIAL MEDIA
}

\author{
José Ignacio Peláez, Gustavo Vaccaro, Francisco E. Cabrera \\ Metric and Intangibles Management Chair. IBIMA. Department of Languages and Computer \\ Sciences. University of Malaga (SPAIN)
}

\begin{abstract}
Social Risk in education such as bullying, are usually invisible to teachers and parents, at all educational levels. However, these risks remain a reality everywhere in the world, turning into a problem that is rapidly globalizing due to the widespread access to the Internet. The Internet has permeated our entire society and is now present in almost every activity. The education and most aspects associated with it, such as Social Risks, are not exempt of this new form of communication within our society. This has led to a significant increase in damage Social Risks can exhort on the victims, due to several causes such as their capacity for dissemination, repetition and virality; greater anonymity of aggressors and the chance for more people joining them; continuity over time even when after school hours; display of intimacy before an endless crowd of people; ease of permanent control through geolocation, control of online statuses and connections; and even the risk of easily impersonating a victim. The first step to prevent these issues is to carry out a study on the current state of Social Risks. An updated snapshot would allow to draw up action plans based on reliable data and develop countermeasures to minimize the damage caused by current Social Risks to minors. The objective of this work is to conduct a study on unsolicited data obtained from Social Media on three of the most prominent Social Risks of our society, namely Bullying, Addictions and Xenophobia within the field of education, with the aim of obtaining an updated snapshot of their current status. The study was carried out during the second semester of 2017 and the first semester of 2018, quantifying the presence and emotion of said risks in Social Media, determining the most relevant terms, as well as the most used communication channels.
\end{abstract}

Keywords: Social Risk, Education Challenges, Bullying, Addictions, Xenophobia, Social Media.

\section{INTRODUCTION}

The idea of risk is related to the imminence or proximity of a potential damage. The term, is therefore linked to the possibility of consummating this damage. The term "social" appears when the action or the fact is related to a society, in the sense of a group of individuals interacting with each other. Consequently, Social Risk is understood as the possibility of a person suffering any damage that has its origin in a social cause, dependent in many cases, on the environmental conditions surrounding the individual (Ajzen \& Fishbein 2005, Buss A. 2014, Issa et al 2016, Siegel 1994).

Given the possibility of there being Social Risks within a population, which is inevitable, it is necessary to take measures, with prevention and the search for solutions being the two fundamental approaches to avoid such risks. Hence, the starting point of any action is to carry out an analysis capable of facilitating an image or snapshot of the society in which Social Risks could be present, that is, it is necessary to know the level of knowledge that the society as a whole has regarding Social Risks; the levels of information that exist in communication channels; the feeling and attitude that society has towards the studied risks and their context; or how they are expressed and the terminology used by the community when they refer to said risk (Agrawal et al 2013, Bennet 1988)

The influence of the internet and new technologies in today's society is undeniable. The Internet has permeated the entire society and is present in almost all of the activities of today's society. Social risks have not been alien to this new form of relationship between people, and this has caused a significant increase of these risks, due to the capacity of this new media for providing diffusion, repetition and virality; greater anonymity of the aggressor and the possibility of more individuals joining; continuity over time; displays of intimacy before a multitude of people; ease of permanent control (geolocation, on-line status control or connections); and even the possibility of easily supplanting the persona of the victim. (IAB 2017). 
Given this new scenario and the raise of these types of cybercrime, this study was carried with the objective of having a snapshot of three of the main social risks in the educational field in Spain within Social Media: bullying, addictions and xenophobia (SOS 2017, UNICEF 2016). This study analyzes, among other things: Their presence in Social Media; the existing feelings towards them by the general public; the way of expressing about these Social Risks; what is being said on each Social Risk; and the communication channels employed for talking about them, their presence, the emotions regarding them, and the terms employed by means of word clouds.

For this purpose, this work has been organized as follows: in the second section the methodology used is presented; in the third section, the results are shown; and in the last section this work ends presenting the conclusions reached.

\section{METHODOLOGY}

\subsection{Study population}

The population universe corresponds to 46.5 million inhabitants (Spain), of which it is estimated that 39.5 million are Internet users and 27 million are active users of social networks. Regarding smartphone users, there are over 37 million users and 23 million people use them for Social Networks. Each individual has the same probability of being included in this study, however, the task of establishing an adequate sample size is complex due to the nature of the opinions expressed in online media. To overcome these difficulties in this study, we took into account communications that express unsolicited opinions when they meet the following inclusion and exclusion criteria:

Inclusion criteria.

- Its author must be aged between 18 y 65 years old, as reported to services and data sources whenever this is available.

- The communication must be public and can be viewed without the need to subscribe to the source of data or explicit permissions of the sender of the communication.

Exclusion criteria.

- Opinions originated from advertising campaigns.

- Opinions generated by procedural methods (bots).

Considering the inclusion and exclusion criteria, and following the Cochran formula for large oblations (Wong et al 1995), we calculated that the sample size must be of at least 400 communications, with a margin of error of $5 \%$, a confidence interval $95 \%$, and considering a random distribution of opinions (between positive and negative), that is, a probability of $50 \%$ of being classified as either of them.

\subsection{Data sources}

The data was obtained from public media, freely available and accessible without restrictions from Spain or internationally. Table 1 shows the data sources for this study.

Table 1. Data sources.

\begin{tabular}{l|l} 
SOURCE & \multicolumn{1}{l}{ NUMBER OF CHANNELS OR VIGILANCE PROBES } \\
\hline TWITTER & 750 vigilance streams in Spanish. \\
FACEBOOK & 210 public social profiles of influencers, enterprises and public figures. \\
YOUTUBE & 400 channels in Spanish. \\
BLOGS & 623 public blogs in Spanish. \\
NEWS MEDIA & 2437 official news media websites. \\
ONLINE CONTENT & 149 channels in Spanish. \\
AGGREGATORS & 4569 data obtaining probes in Spanish.
\end{tabular}




\subsection{Time Period and Procedure of Data Collection}

The monitoring of these data sources was carried out in the time period from September 1, 2017 to March 31, 2018. The strategies for obtaining these data are detailed in Table 2.

Table. 2 Data collection procedures.

SOURCE

DATA COLLECTION PROCEDURE

TWITTER

FACEBOOK

YOUTUBE

\section{BLOGS}

\section{NEWS MEDIA}

\section{ONLINE CONTENT} AGGREGATORS
Twitter Public API.

Public Facebook GRAPH API.

Public YouTube API.

RSS Source.

RSS Source and Web Scraper.

RSS Source, Public API in Reddit's case.

\subsection{GE ${ }^{2}$ AN Methodology}

The model employed to carry out this study is the $\mathrm{GE}^{2} \mathrm{AN}$ model (figure 1) (Peláez et al 2017, Peláez et al 2018). This model is a cause-effect emotion model, developed by the Metric and Intangibles Management Chair of the University of Malaga, and endorsed by the main Spanish companies comprising the Foro de Reputación Corporativa de España (INTED 2018). This model adds new relationships and elements to the reputational cause-effect model of Macmillan, Money and Hillebrand (2005).

$\mathrm{GE}^{2} \mathrm{AN}$ is a model that consists of 5 phases in its entirety, and was originally designed for the holistic management of intangibles in organizations, allowing to establish cause-effect relationships in any environment, where there are intangible magnitudes, such as emotion or sentiment (Buss D. 2014, Chintana 2012, Jiang et al 2016). That is why, this model is very suitable to determine, from a campaign and its impact on society; the emotion that society has on something, or explain why the public has a certain emotion.

The characteristics that define the model are the following:

1 Five-stage model: Management, Experience, Emotion, Attitudes, Business.

2 Cause-effect model relationship deriving from emotions.

3 Holistic transversal model that connects intangibles and tangible variables.

4 Addition of new stages in the precedents (Management) while incorporating attitudes on the consequence stages.

5 It allows the quantification of value creation in the relations of organizations with their publics and its subsequent impact.

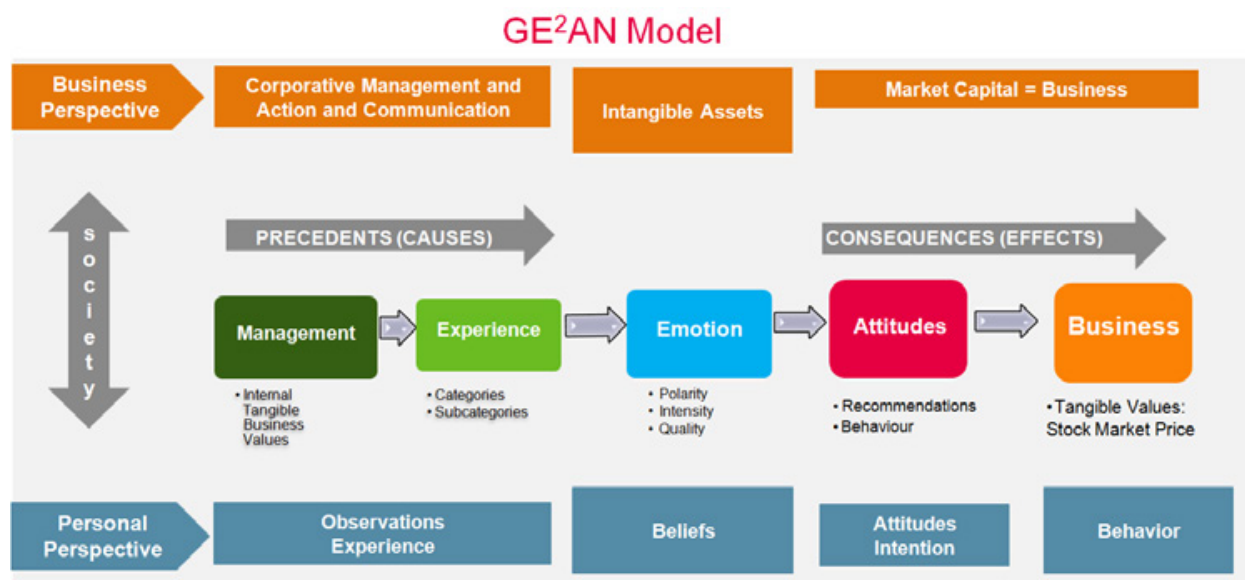

Figure 1. Intangibles Transversal Management Model GE ${ }^{2}$ AN. Source: Compiled by authors. 


\subsection{Possible Biases of Measurement Surveys}

Due to the nature of this study and the technologies that are used, there are no biases such as those found on traditional studies that use surveys. This study analyzes all the communications on the subject that users provide in the studied media; therefore, since the analyzed information is unsolicited and provided willingly by internet users, biases usually presented on traditional surveys as the direct response bias, as well as other biases such as memory, random selection procedure, of membership or permanence or non-response, among others are not present.

\section{RESULTS}

\subsection{Bullying}

In the case of bullying, the most relevant terms in the communications issued by the public are those related to prevention. In the word cloud of figure 2, you can see that terms such as "disciplina" (discipline), "prevenir" (prevent) and "campaña" (campaign) are widely used within the scope of bullying, which demonstrates the demand for tools to tackle the problem before it occurs or prevent it from going further. Also quite noticeable is the interest in the various campaigns and mechanisms to detect situations and denounce harassers as a measure to achieve a better coexistence in class. Finally, within the concerns about school bullying the interest is focused on those cases in which they reach the point of insult or physical aggression. These cases exhibit a widespread rejection by social media users.

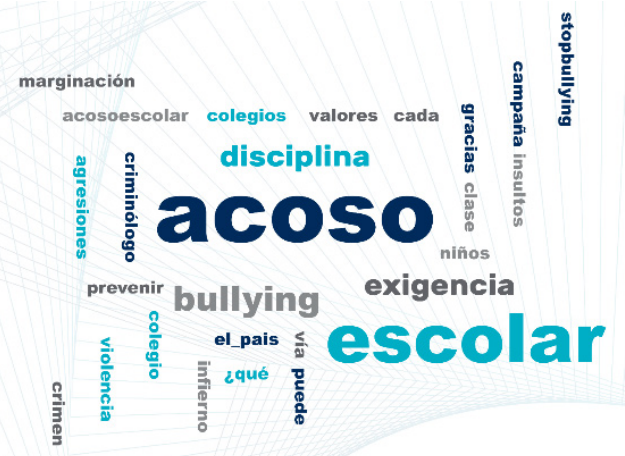

Figure 2. Word cloud of relevant terms on bullying.

In relation to communication the channels, communications related to the social problem of bullying were issued mostly through Twitter, followed by Facebook, News Media, News Aggregators and YouTube. Figure 3 shows the proportion of communications per data source.

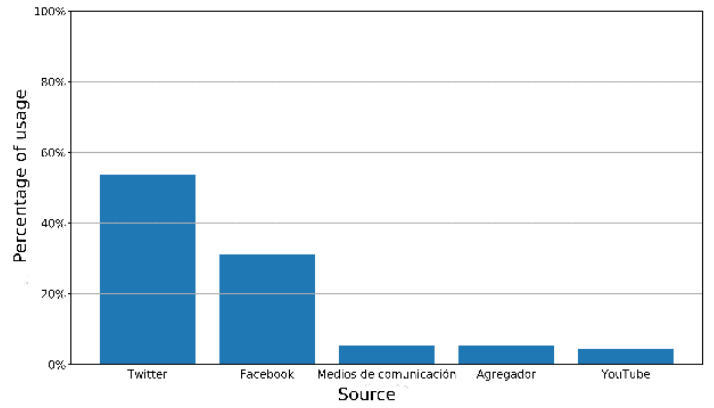

Figure 3. Communications in proportion to data sources on bullying.

Lastly, in relation to the emotion expressed within the communications, a generalized rejection is detected, with important peaks of rejection when a bullying case takes place. 


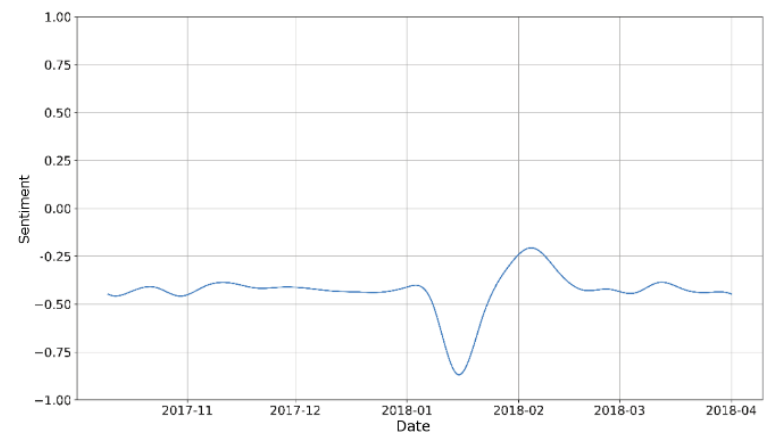

Figure 4. Sentiments expressed in social media about bullying.

\subsection{Addictions}

In the case of addictions, the most relevant terms in communications issued by the public are those related to substances. In the word cloud of figure 5, one can observe terms "drogas" (drugs), "cocaina" (cocaine), "cannabis" and "porros" (joint) are widely used within the field of addictions. In addition, it is important to note that the term "móvil" (mobile phone) is in a predominant position in the cloud of relevant terms, which reflects a concern about the abuse of the use of mobile phones, especially by teenagers. On the other hand, the presence of the term "valores" (principles) in the word cloud reflects a pattern in opinions, where principles become the positive counterweight to the negativity inherent in addictions.

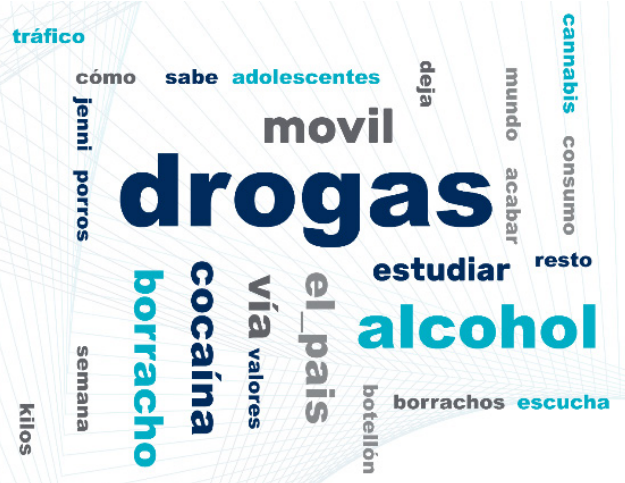

Figure 5. Word cloud of relevant terms on addictions.

The most predominant channel for communications on the Social Risk of addictions is Twitter, followed by Facebook, YouTube, News Media, and News Aggregators. Figure 6 shows the proportion of communications per data source.

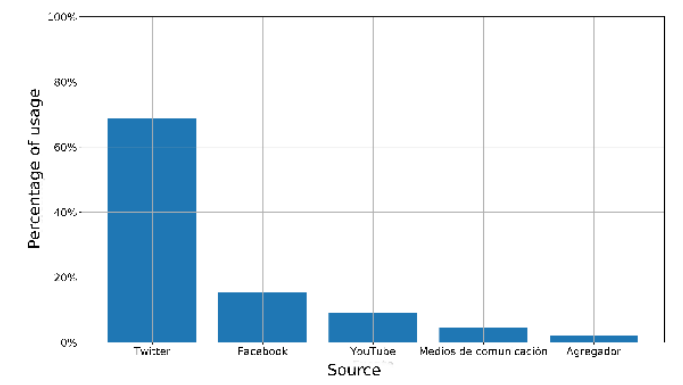

Figure 6. Communications in proportion to data sources on addictions.

Lastly, in relation to the emotion expressed by communications, a mostly neutral trend in communications is detected. 


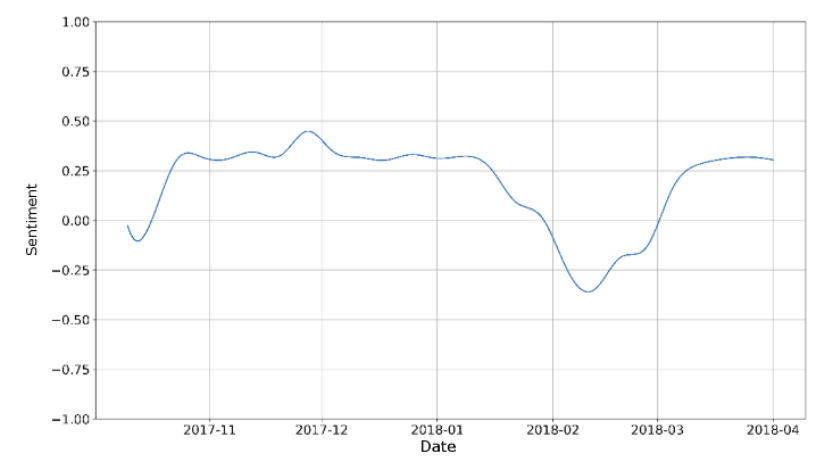

Figure 7. Sentiments expressed in social media about addictions.

\subsection{Racism and Xenophobia}

The word cloud about xenophobia in Figure 8 shows that in the case of immigration, common terms are used to refer to the country of origin of the immigrants. The topic that has generated most communications during the study period is the refugee crisis, although the opinions generated in this regard are usually generated in response to some news published in the media. On racism itself, racist attitudes tend to generate rejection towards those who manifest them and the most widespread concern is usually related to illegal immigration.
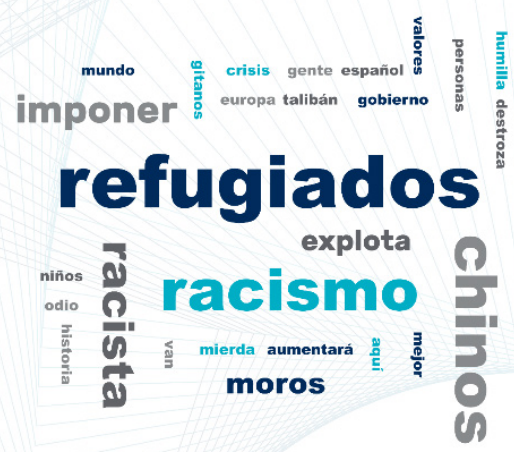

Figure 8. Word cloud of relevant terms on xenophobia.

Communication related to the social problem of xenophobia were issued through Twitter, followed by Facebook, News Media, News Aggregators and YouTube. Figure 9 shows the proportion of communications per data source.

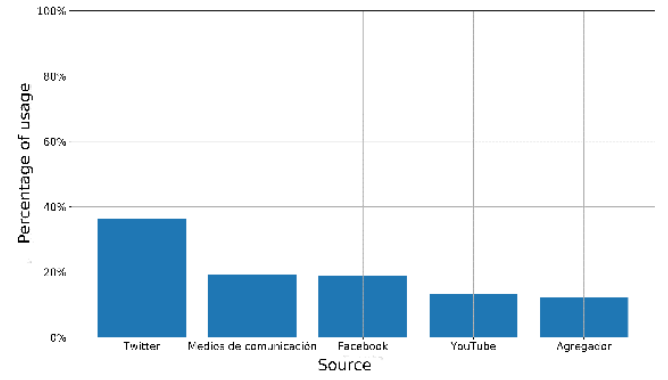

Figure 9. Communications in proportion to data sources on xenophobia.

On the emotion expressed in these communications, a generalized sentiment of rejection is shown, with important peaks of acceptance when an event related to the application of the law occurs against those who exercise violence or support illegal immigration. 


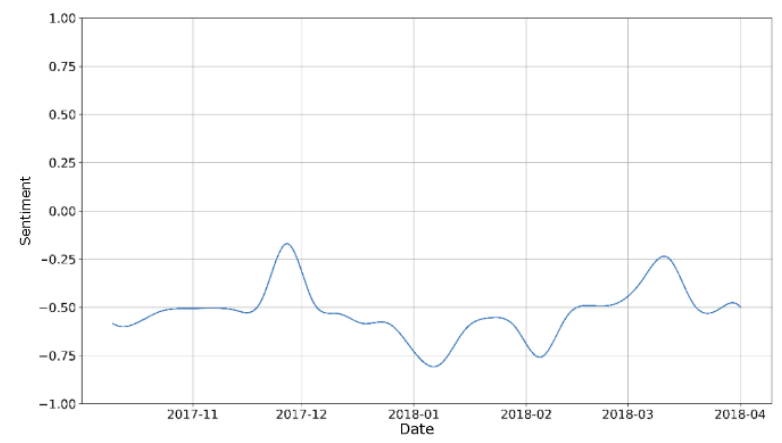

Figure 10. Sentiments expressed in social media about xenophobia.

\section{CONCLUSIONS}

In this work a study has been carried out with the objective of having a snapshot of Social Media users on three of the main Social Risks in the Spanish educational field: bullying, addictions and xenophobia.

The study has been based on unsolicited communications, which have been issued freely by people in different digital ecosystems in Spain. The study has shown different results, both in terms of sentiment, communication channels used and their importance in relation to the study risks, or terms used in the disseminated communications. Among the different conclusions that have been extracted in this study, and that are related to educational environments and the risks of study, we can conclude the following:

Bullying

- Discipline and the level of demand are considered fundamental factors to combat bullying in the classroom.

- The perception of the discipline and the level of demand as positive aspects is greater in younger students than in parents.

- Students demand more authority and more commitment from schools to combat acts of bullying.

Xenophobia

- School-age students do not have generalized negative feelings towards people from other countries.

- Students present negative feelings towards people of other nationalities, when trying to impose their culture on them.

- School-age students show a positive sentiment towards legal immigration and immigrants who are tricked into being exploited. While they present a negative feeling towards illegal immigration.

\section{Addictions}

- The use of mobile phones and how to manage them is one of the main topics of consultation of parents in social media.

- Alcohol is not perceived as an addiction but as a social facilitator by young people.

- Comments and inquiries about substances of medical use among students are detected to increase school performance.

\section{REFERENCES}

[1] Agrawal, N., Han, D., \& Duhachek, A. (2013). Emotional agency appraisals influence responses to preference inconsistent information. Organizational Behavior and Human Decision Processes, 120, 87-97. 
[2] Ajzen, I., \& Fishbein, M. (2005). The influence of attitudes on behaviour. In: The handbook of attitudes, 173-221.

[3] Bennett, F. C. (1988). Neurodevelopmental outcome in low birth weight infants: The role of developmental intervention. Clinics in Critical Care Medicine, 13, 221-249.

[4] Buss, A. H. (2014). Personality: Evolutionary heritage and human distinctiveness. London: Psychology Press.

[5] Buss, D.M. (2014). Comment: Evolutionary criteria for considering an emotion "basic": Jealousy as an illustration. Emotion Review, 6, 313-315.

[6] Chintala, S. (2012). Sentiment Analysis using neural architectures. New York: New York University.

[7] Issa T., Isaias P., Kommers P. (2016) Social Networking. In: Issa T., Isaias P., Kommers P. (eds) Social Networking and Education. Lecture Notes in Social Networks. Springer, Cham

[8] Jiang, H., Liang, J., Wang, H., \& Sun, P. (2016). The interplay of emotions, elaboration, and ambivalence on attitude-behavior consistency. Journal of Consumer Behaviour, 15(2), 126-135.

[9] MacMillan, K., Money, K., Downing, S., \& Hillenbrand, C. (2005). Reputation in Relationship: Measuring Experiences, Emotions and Behaviours. Corporate Reputation Review, 8, 214-232.

[10] Peláez J.I, Casado A, Yanez Estela, Cabrera F, Yanez A. 2017. A Model for Social Assessment of Governmental Areas Thorough Intangible Assets. Conference ICEDEG 2017.

[11] Peláez J.I. Cabrera F, Vargas L. 2018. Estimating the Importance of Consumer Purchasing Criteria in Digital Ecosystems. Knowledge-Based Systems.

[12] Siegel, L. S. (1994). The long-term prognosis of pre-term infants: Conceptual, methodological, and ethical issues. Human Nature, 5, 103-126.

[13] Wong, Chi Song, and Tonghui Wang. "Laplace-Wishart Distributions and Cochran Theorems." Sankhyā: The Indian Journal of Statistics, Series A (1961-2002), vol. 57, no. 3, 1995, pp. 342359. JSTOR, JSTOR, www.jstor.org/stable/25051061.

[14] Estudio Anual Redes Sociales (2018). IAB Spain. https://iabspain.es/wpcontent/uploads/estudio-redes-sociales-2018_vreducida.pdf.

[15] Informe Annual 2017 sobre el Racismo en el Estado Español. 2017. SOS Racismo. ISBN: 97884-96993-61-7

[16] INTED. Informes de Intangibles INTED.2018. Fundación Corporate Excellence. Centre for Reputation Leadership. http://www.corporateexcellence.org/index.php/Compartimosconocimiento/l-Informe-de-Activos-Intangibles-en-Ecosistemas-Digitales-INTED

[17] Equidad para los Niños. El caso de España. 2016. Unicef. 